NBER WORKING PAPER SERIES

\title{
SIMULATING THE TRANSMISSION OF WEALTH INEQUALITY VIA BEQUESTS
}

\author{
Jagadeesh Gokhale \\ Laurence J. Kotlikoff \\ James Sefton \\ Martin Weale
}

\author{
Working Paper 7183 \\ http://www.nber.org/papers/w7183 \\ NATIONAL BUREAU OF ECONOMIC RESEARCH \\ 1050 Massachusetts Avenue \\ Cambridge, MA 02138 \\ June 1999
}

We thank Steven Caldwell for providing fertility data from CORSIM, his detailed micro simulation model of the U.S. economy. We thank Pierre Pestieau and other participants of the ISPE conference on Bequests and Inequality Across Generations, participants at the Federal Reserve System's Committee on Money and Macroeconomics, James Poterba, and two referees for very valuable comments. Laurence J. Kotlikoff gratefully acknowledges research support from the National Institute of Aging. All opinions expressed are those of the authors and not those of the National Bureau of Economic Research, Boston University, the Federal Reserve Bank of Cleveland, or the National Institute for Economic and Social Research.

(C) 1999 by Jagadeesh Gokhale, Laurence J. Kotlikoff, James Sefton, and Martin Weale. All rights reserved. Short sections of text, not to exceed two paragraphs, may be quoted without explicit permission provided that full credit, including $($ notice, is given to the source. 
Simulating the Transmission of Wealth

Inequality via Bequests

Jagadeesh Gokhale, Laurence J. Kotlikoff,

James Sefton, and Martin Weale

NBER Working Paper No. 7183

June 1999

JEL No. D31

\begin{abstract}
This paper develops, calibrates, and simulates a dynamic 88-period OLG model to study the intergenerational transmission of U.S. wealth inequality via bequests. The model features marriage, realistic fertility patterns, random death, assortative mating based on skills, heterogeneous skill endowments, heterogeneous rates of return, skill inheritability, progressive income taxation, and resource annuitization via social security. All bequests arise from imperfect annuitization. Nonetheless, the model generates a realistic ration of aggregate wealth to aggregate labor income, a realistic bequest flow relative to the stock of wealth, and a realistic wealth distribution at retirement. Skill differences, assortative mating, social security, and the time preference are the primary determinants of wealth inequality. Bequests do propagate wealth inequality, but only in the presence of social security, which disproportionately disinherits the lifetime poor. Intergenerational wealth immobility, also considered here, is primarily determined by the inheritance of skills from one's parents and the magnification of the impact of this inheritance by marital sorting.
\end{abstract}

Jagadeesh Gokhale

Federal Reserve Bank of Cleveland

1455 East 6th Street

Cleveland, OH 44101

jagadeesh.j.gokhale@clev.frb.org

James Sefton

National Institute of Economic and Social

Research

2 Dean Trench Street

Smith Square

London SW1P 3HE

UK

m.weale@niesr.ac.uk
Laurence J. Kotlikoff

Department of Economics

Boston University

270 Bay State Road

Boston, MA 02215

and NBER

kotlikof@bu.edu

Martin Weale

National Institute of Economic and Social Research

2 Dean Trench Street

Smith Square

London SW1P 3HE

UK

jsefton@,niesr.ac.uk 


\section{Introduction}

Does inequality in inherited wealth exacerbate wealth inequality? If so, by how much? These fundamental questions remain unresolved. Although it may seem counterintuitive, inherited wealth may be more evenly distributed than non-inherited wealth and may reduce overall wealth inequality. The reason is that the distribution of inheritances is largely governed by the random nature of longevity whereas the distribution of non-inherited wealth is largely governed by the distribution of labor earnings.

Theoretical research has identified many of the channels through which inheritances influence wealth inequality, but their relative importance is unresolved. Empirical analysis of inheritances has been limited by the availability of reliable data. An alternative approach initiated by Blinder (1974, 1976) and Davies (1982), and the one taken here, is to simulate the transmission of inequality via bequests. Unlike previous simulation studies, however, our focus is on unintended inheritances arising from random dates of death and the dynamic impact of these inheritances on the distribution of wealth.

To study this process, we construct an overlapping generations model with uncertain lifespan. Each agent lives for at most 88 years - the first 22 years as a child, the second 22 years as a young adult who marries and has children, the third 22 years as a married, middle-aged adult who has no additional children, and the last 22 years as a married or widowed older adult facing lifespan uncertainty. Agents who die prior to reaching age 88 bequeath their wealth to their spouses. If their spouses are no longer living, they bequeath in equal amounts to their children, all of whom are alive given the model's timing. Agents have life-cycle preferences, meaning they have no bequest 
motive per se and leave bequests only because their resources are not fully annuitized. Our model follows the economy and its existing and new agents through time. This is a prerequisite to determining the impact of random inheritances on the long-run distribution of wealth.

The bequest/inheritance process is complicated. Other things equal, children whose parents die relatively early receive larger inheritances than children whose parents die relatively late. But how much one inherits depends both on the number of one's siblings sharing the bequest and on the amount of non-annuitized wealth one's parents accumulate prior to their deaths. Parents' wealth accumulation depends, in turn, on how much they themselves inherited (which depends on when their ancestors died), the level of their earnings out of which they saved, the rate of return they received on their savings, the number of children they had to support, and their own time-preference rates (which influences their desire to save). Hence, earnings inequality, the transmission of earnings inequality across generations, the number and spacing of children, assortative mating, heterogeneous rates of return, time preference, the annuitization of retirement savings through social security, and the progressivity of the income tax system can all play important roles in influencing inequality in inheritances. We consider each of these factors and their interactions in trying to account for wealth inequality and immobility.

To parse our life-cycle effects and to ensure that we capture the receipts of all inheritances, we measure intra-cohort wealth inequality at retirement. In studying wealth mobility, we consider the wealth holdings of the children of rich and poor retirees when these children reach retirement. Our results suggest that whether inheritances dampen or exacerbate wealth inequality depends very strongly on social security's annuitization of 
retirement savings. Absent social security, inheritances somewhat reduce wealth inequality among members of the same birth cohort. In social security's presence. however. inheritances play an important role in increasing wealth inequality. Social security aside, the main determinants of our model's wealth inequality are inequality in lifetime earnings (skill differences), assortative mating based on skills, and the rate of time preference. Interestingly, holding constant inequality in skills, the fact that agents inherit their skills from their parents does not materially alter wealth inequality.

When all of the factors that influence wealth inequality are included and calibrated to what appear to be the most realistic set of parameter values, our model generates a distribution of wealth that closely approximate the degree of inequality and skewness in the actual U.S. data. In particular, the richest 1 percent of our model's retiring households hold 32.8 percent of total wealth, which is quite close to the corresponding 30.4 percent figure in the Survey of Consumer Finances. Our model also generates what appears to be a reasonable degree of wealth immobility. Under our most realistic set of assumptions, 15.9 percent of the children of the super rich end up super rich themselves.

Our findings are striking, but their relevance to the U.S. economy is a matter of opinion. True, we've considered a large set of important determinants of wealth inequality. But we haven't considered all determinants; and although we've tried to calibrate the model carefully, our calibration is limited by the availability of data. These points should be kept in mind in judging whether this paper's findings are telling us about the real world or just about the life-cycle model. 
The paper proceeds in Section II with a literature review. Section III presents our simulation model and its calibration. Section IV presents simulation results. Our strategy here is to start with extreme assumptions to illustrate the roles played by different factors and then turn to a more realistic set of assumptions. Section $\mathrm{V}$ discusses the impact of inheritances on the transmission of wealth inequality across generations, and Section VI summarizes and concludes the paper.

\section{Literature Review}

Early studies of the link between inheritance and inequality focussed on the relationship between the values of the estates of fathers and their sons (Wedgwood, 1929, Harbury and Hitchens, 1979). Wedgwood considered a sample of 99 people who left estates of at least $£ 200,000$ (just under $\$ 1,000,000$ ) between 1924 and 1925 . He found that 60 percent had a predecessor who died leaving at least $£ 50,000$, and that about one third of the wealthy owed their position entirely to inheritance. Harbury and Hitchens reported that in 1973,58 percent of those men who died leaving at least $£ 100,000$ had fathers who had left at least $£ 25,000$ at 1973 prices and that 67 percent of the variance in a son's estate was explained by the variation in the father's estate.

Interesting as they are, these data do not prove that inherited wealth is a source of inequality. The data relate to the total value of the father's estate and not to the amount inherited by the son, which may have been much less if the estate was divided equally among a number of children. And they are perfectly consistent with the view that wealthy fathers endowed their children with other advantages in life that helped them 
become wealthy. Nevertheless they reinforce the widely held view summarized by Meade (1976) that inheritance is a source of inequality in the distribution of wealth, a conclusion supported by the theoretical model of Wilhelm (1997) and the empirical work of Menchik (1979). This view underlies support for estate taxation as a potential mechanism for redistributing wealth.

The alternative idea -- that intergenerational transfers can be equalizing -- can be traced to Stiglitz (1969). In common with most of the growth literature of the day, Stiglitz assumed that each individual's consumption was a linear function of her total income. He demonstrated that a stable, egalitarian distribution of wealth would emerge if inheritances were distributed evenly among all of one's children.

Subsequent work focussed on the impact of inheritance on income inequality rather than wealth inequality. Stiglitz and Atkinson (1980) used the same model, but added earnings heterogeneity, to show that an increase in the size of inheritances, caused by an increase in the rate of savings, would decrease income inequality. In essence, inheritances act as insurance against the random receipt of lower than average labor income. If an agent's earnings end up below (above) the average for his cohort, chances are his parents' earnings were higher (lower), and their bequest will permit his parents to share with him their better (worse) luck. Stiglitz and Atkinson also pointed out that for inheritances to increase inequality in these linear models an additional mechanism needed to operate to offset this insurance effect. Stiglitz (1969) suggested primogeniture (the oldest son receives the entire estate). Blinder (1973) suggested class mating.

\footnotetext{
'Davies and Shurrocks (2000) provide an excellent review of the literature.
} 
The models of Becker and Tomes (1979) and Tomes (1981) highlight the joint role that inheritances of financial wealth and earning power (human capital) play in determining whether intergenerational transfers are equalizing. Their condition for this outcome is that the propensity of parents to transfer financial and tangible resources to their children exceeds the inheritability of human capital -- the correlation coefficient between the parent's and the child's human capital. Deardon. Machin and Reed (1997) and Solon (1992) and Solon and Zimmerman (1992) have recently tried to estimate the inheritability of human capital in the United Kingdom and the United States, respectively. Their results suggest a coefficient of 0.5 for the correlation between a father's and a son's earnings. Although this is a large correlation, it's not clear whether it arises because of genetics or parents' human capital investment in their children.

Laitner (1979a and 1979b) constructs a utility-maximizing framework in which parents care about both their own and their children's consumption, bequests must be non-negative, and there is no inheritability of human capital. He shows that an equilibrium wealth distribution exists and that inheritances are equalizing if there is no assortative mating. The studies of Meade (1964), Stiglitz (1969), Pryor (1973), Atkinson and Harrison (1978), and Atkinson (1980) also point to the role of imperfect correlation of spouses' inheritances in equalizing the distribution of inheritances.

Theoretical work on taxation provides additional grounds for believing that inheritances are equalizing. Becker and Tomes (1979) and Atkinson and Stiglitz (1980) show that inheritance taxation can increase income inequality. However if there are incomplete markets, such as the market for educational loans considered by Loury (1981), redistributive taxation of bequests can reduce intragenerational inequality. 
The question of whether inheritances increase or decrease income inequality has also been studied empirically. Tomes (1981) examined this question directly and found evidence in support of an equalizing effect. Davies and Kuhn (1991) suggest that even though inheritances are equalizing in the long run, a rise in inheritance taxation will reduce inequality in the short run, but raise it in the long run.

\section{Previous Simulation Studies}

The simulation literature descends from Atkinson's (1971), Flemming's (1976), Oulton's (1976), and Wolfson's (1977) analyses of whether a pure (no-bequest) life-cycle model can explain wealth inequality. The general conclusion of this work is that, sans bequests, the life-cycle model is unable to explain the extreme upper tail of the wealth distribution. For example, Atkinson found wealth shares of the richest 1 and 5 percent of just 2 percent and 10 percent. As pointed out by Davies and Shorrocks (1978), Oulton's (1976) addition to the Atkinson model of a more realistic earnings distribution raised these shares to 6 and 17 percent. These figures are far below the actual U.S. shares.

Blinder (1974, 1976) conducts simulation studies with both intragenerational heterogeneity and life-cycle accumulation. He finds that inheritances are unimportant in determining inequality of annual income and that there is high intergenerational mobility in the distribution of inherited wealth. Unfortunately, he doesn't consider the impact of inheritances on the distribution of total wealth.

Wolfson (1979) and Davies (1982) simulate a behavioral model of life cycle saving and desired bequests. For example, in Davies' Canadian study parents maximize a lifetime utility function defined over their own and their adult childrens' consumption 
subject to their own and their childrens' lifetime budget constraints. ' Davies' crosssection wealth and income distributions closely match the corresponding 1970 Canadian distributions. ${ }^{3}$ Davies explored only the role of intentional bequests on inequality and in a static context; i.e., he did not consider how the receipt of inheritances by one generation would influence the receipt of inheritances by the next generation and so on. In contrast, the bequests in our model are purely unintentional. They are also random, and this randomness requires tracing their influence over successive generations; i.e., it necessitates a dynamic approach.

Huggett (1996) develops a large-scale life-cycle simulation model with uncertain lifetimes as well as uncertain labor income that follows an autoregressive process. He compares the model's age-wealth distribution to the actual U.S. distribution and finds a fairly close match except at the very upper tail. But unlike our analysis, which considers how the distribution of inheritances alters the distribution of wealth, Huggett assumes that all bequests are collected by the government and divided evenly across the population.

The closest antecedent to our study is that of Flemming (1979). Like us, Flemming considers earnings heterogeneity and unintended bequests arising from

\footnotetext{
2Optimal consumption over a fixed and certain lifespan is simulated for 500 couples. Each parent couple is identical on all but the following dimensions: Parents' own inheritances, earnings, rate of return, rate of time preference, intensity of altruism toward children, and parents: age of first birth. Random draws of these variables from distributions calibrated to Canadian data are allocated to each couple before computing its optimal consumption path and desired bequest. Bequests occur when parents die, which, given there is no lifespan uncertainty, occurs at a common age. Bequests are distributed among children equally or, alternatively, in a compensatory manner based on children's earnings. Assuming constant rates of income and population growth over time, a single simulation over 500 couples suffices to generate a cross-section distribution of wealth, income, and lifetime resources.

${ }^{3}$ Davies also attempts to explore the impact of the different sources of heterogeneity on inequality. Unfortunately, the multi-generation (dynamic) simulations required to explore the long-run level of bequests and inequality from resulting from removing, in turn, the heterogeneity in each of the variables was precluded by limits on computational capacity. Consequently, Davies was forced to consider these experiments assuming no bequests.
} 
uncertain lifetimes and imperfect annuitization. But he also examines intentional bequests and the inheritablity of skills. In contrast to our approach, Flemming's model has parthenogenesis; i.e., there is no marriage. There is also no heterogeneity in the number and spacing of children. Flemming finds that wealth is much more unequally divided than is earnings, that random mortality in the absence of annuities and desired bequests can increase wealth inequality by roughly a third, and that intentional bequests can play an additional important role in raising wealth inequality.

\section{Empirical Evidence on Altruism}

Since our model ignores intended bequests, it's important to consider past research that has examined the motives underlying bequests. Laitner and Juster (1996) find some limited support for altruism in the decision at retirement of most TIAA-CREF participants not to annuitize fully their TIAA-CREF balances. In contrast, Boskin and Kotlikoff (1985), Altonji, Hayashi and Kotlikoff (1992, 1997), Abel and Kotlikoff (1994), Hayashi, Altonji, and Kotlikoff (1996), Gokhale, Kotlikoff, and Sabelhaus (1996), and Wilhelm (1996) show that a) the distribution of consumption across cohorts is very strongly dependent on the cross-cohort distribution of resources, b) the distribution of consumption within extended families is very strongly dependent on the distribution of resources within extended families, c) that taking a dollar from a child and handing it to parents who are actively transferring income to that child leads the parent to hand back only 13 cents to the child, d) that the very major postwar increase in the annuitization of the resources of the elderly has not been even partially offset by an increase in their holdings of life insurance. and e) that the vast majority of bequests are 
distributed equally among children independent of their economic needs. Individually and as a group, these studies constitute very strong evidence against intergenerational altruism, suggesting that most bequests may be unintended or motivated by non-altruistic considerations.

Hurd (1992) examines the influence of children on saving by elderly people in the United States. He finds that the elderly with children do save more than those without, but that the effect is statistically insignificant. Thus his findings are consistent with a view that bequests are largely accidental. According to his simulations, the bequest motive is not only statistically insignificant; it's also small in absolute terms.

It is frequently observed that retired consumers save rather than dissave. Prima facie this might indicate a bequest motive in some form (Hurd, 1990). However Gokhale, Kotlikoff, and Sabelhaus (1996) and Miles (1997) point out that when wealth is calculated to include the capitalized value of social security receipts, it falls throughout retirement. Hurd also concludes from a careful analysis of panel and cross-section data that the evidence on wealth change is consistent with the life-cycle hypothesis and the view that bequests are accidental.

A final point concerning the likelihood of altruistic bequests was made by Meade (1966) and Flemming (1976). They pointed out that anything less than very strong altruism would not suffice to generate ubiquitous and significant bequests given that, on average, the lifetime incomes of children significantly exceed those of their parents.

\section{Evidence on Intergenerational Mobility}


Paul Menchik's (1979) laborious study of wealth immobility appears to be the most detailed analysis of wealth mobility in the U.S. Menchik examined probate records of 1,050 Connecticut residents who passed away in the 1930s and 1940s. Each of these decedents left an estate of $\$ 40,000$ or more. Armed with these records, Menchik tried to track down probate records of the spouses and well over 1,000 children of the 1,050 decedents. His search ended up locating only 199 children for whom probate records were available for both parents. Menchik then considered the correlation between different measures of parental wealth (such as the average of the father's and mother's estates) with the estates of their decedent children. Menchik reports a child-parent wealth correlation of close to .5 and concludes there is fairly high wealth immobility. ${ }^{+}$

\section{The Model and Its Calibration}

This section describes the model's demographic structure, its marital arrangements, its fertility patterns, its method of constructing an initial distribution of the population. its method of populating the model through time, its allocation of skills to the model's agents, its determination of bequests and inheritance, its time-zero wealth distribution, the length of its simulations, and its consumption and saving behavior.

\footnotetext{
+ Menchik's findings are suggestive of wealth immobility, but are certainly not definitive evidence. First, the sample is quite small. Second, there are major issues of sample selection, foremost of which is that the 1,050 original decedents are hardly representative of the population as a whole. $\$ 40,000$ was a considerable sum in the 1930s and 1940s, and the parent-child wealth correlation might be quite different in a complete and random sample. Third, the ages of death of both parents and children are highly varied, and there is no correction for life-cycle differences in wealth accumulation by age. Thus the high parentchild wealth correlation could simply reflect a correlation in the ages of death of parents and children. Finally, most of the 199 children are married, but there is no analysis of the correlation of the household wealth of the child and that of the child's spouse's parents (the child's in-laws). If the children of the rich tend to marry children of the middle and poorer classes, their spouse's parents will likely have modest amounts of wealth. Were they included in the sample, the parental-child wealth correlation might be much lower than Menchik reports.
} 


\section{Demographic Structure}

Agents in the model can live for 88 periods. All economic and demographic events (like earnings, consumption, marriages, births, deaths, wealth transfers and so on) occur at the end of each period. Agents are children during their first 22 periods of life and consume as part of their parent's households at ages 1 through 22. Agents marry on their $22^{\text {nd }}$ birthday. They give birth to children at ages 22 through 43 , depending on their draw from a "birth matrix" described below. They also enter the work force on their $22^{\text {nd }}$ birthday (receiving their first paycheck at age 23), and work through age 66 . They face positive probabilities of dying between ages 67 and 88 . The probability of an agent's dying on her $88^{\text {th }}$ birthday given that she has lived to that date is one. The probabilities of dying at ages 67 through 87 are taken from U.S. mortality statistics. The number, sexes, and timing of children born to each couple are determined randomly as discussed below. This distribution is aligned to ensure that an equal number of males and females - 2000 -are born each year. Hence, each cohort is of equal size and there is no population growth:

\section{$\underline{\text { Marriage }}$}

Agents marry at age 22, either on a random basis or on the basis of their skill (the present value of their lifetime earnings). In the later case of assortative mating, agents are married based on their skill rank, with the top skilled female marrying the top skilled male, the next most skilled female marrying the next most skilled male, and so on.

\section{Fertility}


An initial population (at time $\mathrm{t}=0$ ) of 4000 thousand individuals ( 2000 males and 2000 females) was created for each age between 0 and 87 . First, a matrix of "birth ages" was derived from a fertility simulation of CORSIM - a dynamic microsimulation model of the U.S. economy described in Caldwell et al. (1998). The simulation considered 40.434 females born between 1945 and 2000 and recorded their ages of giving birth if those ages fell between ages 22 and 43. For each female in our CORSIM sample, we stored this information in our CORSIM birth matrix that accommodates a maximum of 10 birth ages, 5 for male and 5 for female births. Thus, the matrix has 40,434 rows and 10 columns. Table 1.1 shows the distribution of females in the matrix by number and sex of births.

Since, computer memory limitations allowed us to process only 4000 individuals in each year of birth, we needed to pare down our birth matrix to end up with a modified birth matrix that contains exactly 2000 male births and 2000 female births. We started by selecting 2000 rows from the birth matrix. The selection was done at random without replacement except that rows containing more than 5 births were excluded. The total number of births in the selected 2000-row matrix exceeded 4000 . Hence, we randomly eliminated male and female births in the rows of this matrix for rows containing more than one birth until we were left with precisely 2000 male and 2000 female births. This guaranteed that the 2000 rows of the final birth matrix would generate exactly 2000 female and 2000 male births. Table 1.2 shows the distribution of females by the number and sex of their births in the birth matrix used in the simulation. 
Populating the Model at Time Zero

We populated our model by first creating 2000 male and 2000 female old-adults for each age between 67 and 88 . These males and females were then married to each other sequentially. Some of these oldsters were treated as dead when we initiate the simulation. But we needed to include their ghosts at this stage of our process of populating the model in order to establish complete family trees. Marriage was allowed only between people of the same age to be consistent with our assumption that marriage occurs at age 22 (i.e., that initial oldster males married initial oldster females when they were 22 and their wives were 22). Family relationships were established by exchanging id numbers. For example, marriage involves entering the spouse's id numbers in the spouse-id location of each person's record. Oldsters have no living parents or grandparents.

Drawing from the 2000 thousand rows of the birth matrix at random and without replacement, the middle-aged and young-adult children of the initial oldsters are created, ranging in age from 24 through 66 . Take, for example, the initial 70 -year olds. For each 70 year-old female (including the ghosts), we assigned a row of the birth matrix drawn at random without replacement. This row indicates how many children the female had and the ages at which she had them. We repeated this process of drawing at random without replacement from the birth matrix for each cohort of oldster females; i.e., we did it for 66 year-old oldster females, 67 year-old oldster females, and so on through 87 year-old oldster females. In this process, we do not permit oldsters to bear children in their twilight years, rather we are retrospectively considering the births of the initial oldsters 
when they were in their child-bearing years. When each child is created, the parents' id numbers and years of birth are entered in the child's record, and the child's id number and year of birth is entered in each of the parent's record.

Given that females give birth between the ages of 22 and 43 , oldsters aged 88 at the initiation of our simulation $(t=0)$ have children who are aged 45 through 66 ; oldsters aged 87 at $\mathrm{t}=0$ have children aged 44 through age 65 ; and so on, until we reach oldsters aged 67 at $t=0$ who would have children aged between 24 and 45 . Thus, at this stage of our populating procedure, exactly 4000 (the full compliment of) 45 year-olds and less than 4000 thousand individuals at other ages between 24 and 66 have been created. The reason is that everyone (including oldster ghosts) who could have given birth to 45 yearolds has been considered, but not everyone who gave birth to those between ages 24 and 44 and those between ages 46 and 66 has been considered. For example, some of those aged 25 are children of the current middle aged rather than of the current oldsters (including the ghosts), and some of those aged 50 are children of ghosts who are older than the current oldsters.

Since at this stage there are fewer than 4000 middle-aged males and females at ages 46-66, additional middle-aged males and females are created such that they total 4000 for each of these age groups. Next, all middle-aged males and females (those aged 45 through 66) were married at random, making sure that siblings were not married to each other. Next, the children of middle-aged adults were created, again taking draws without replacement from the birth matrix for females of a given age and then doing the same for females of another age until all females age 45 through 66 had been considered. 
The children produced by this process range in age from 2 through $44 .^{5}$ Given that we've already created the children of the $t=0$ oldsters, the addition of these children leave us with exactly 2000 males and 2000 females aged 23 through 44 -the young adults. The procedure just described was also used to marry the young adults.

The next step in the creation of the initial population was creating the children of the $\mathrm{t}=0$ young adults that were born at $\mathrm{t}=-1$ or earlier. Each young-adult female was assigned a row of the birth matrix at random without replacement, and children were created for all birth ages less than the age at $t=0$ of the female in question. For example, a 44 year-old female's children were created for birth ages between 22 and 43 , but a 23 year-old's children are created only if her birth-row assignment contains a birth-age of 22. That is, children that will be born at $t=0$ or later were not created as yet. At the end of this process, exactly 2000 males and 2000 females had been created for each age between 1 and 88 . The final step in creating the initial population was to kill off oldsters (make the ghosts disappear) according to their cumulative mortality probabilities. ${ }^{6}$

Each person-record contains id numbers and years of birth of the spouse, parents, grandparents, and children. Also recorded is the position of the birth-matrix row selected for each adult household, whether the person is alive or dead and, if dead, the year of death.

\footnotetext{
Sixty-six-year-olds have children aged between 23 and 44; 65 year-olds have children aged between 22 and 43; and so on through 45 year-olds who have children aged between 2 and 23 .

${ }^{6}$ The mortality probabilities are based on U.S. mortality tables. Conditional mortality probabilities below age 67 are set to zero and the conditional mortality probability at age 88 is set to unity. The probability of dying at age $=a, d_{a}$, is calculated as

$\mathrm{d}_{\mathrm{a}}=\left(1-\sigma_{\mathrm{a}}\right) \Pi \sigma_{\mathrm{s}}$,

where $\sigma_{s}$ is the conditional probability of surviving at age $s$.
} 
Populating the Model through Time

In populating the model through time we engaged in the following steps in each year from $t=0$ onward. First, for $t=0$, we allocated at random and without replacement a row from the birth matrix to all 22 year-old females. Second, 22-year-olds males and females were married to each other (at random, or according to their skill ranks depending on the case being considered). Third, females age 22-43 gave birth as determined by their assigned birth matrix row thereby creating 2000 newborn (0-yearold) males and 2000 newborn (0 year-old) females. Fourth, oldsters were killed off at random according to the conditional probability of dying at their respective ages and the existing wealth of those who just died was transferred to the surviving spouse or children. Finally, we aged everyone, excluding those who died, by one year.

\section{$\underline{\text { Skill Endowments }}$}

In our simulations with no skill differences, all working agents are assigned a skill level of 1 and receive an annual wage of $\$ 1$ because we normalize at unity the wage per unit of skill. In the case of skill differences, but no assortative mating, we assign wage profiles to agents when they reach age 23 and begin earning a living. These profiles are derived from CORSIM simulations.

CORSIM simulates wage trajectories for a representative sample of U.S. individuals either alive in 1960 or born thereafter. We use a subsample of 2000 male and 2000 female wage trajectories selected randomly from the CORSIM cohort of individuals born between 1970 and 1974. The wage trajectories are grouth adjusted to conform to the earnings of the cohort born in 1970 (aged 23 in 1993). For example, the wages at 
each age (ranging from 23 through 66) of those born in 1974 are adjusted downward by the compound growth factor applicable between 1970 and 1994. The growth factors are derived from on the U.S. Social Security Administration's average wage index.

These trajectories are placed in two earnings arrays (named $M$ for males and $F$ for females) with 2000 rows and 44 columns in each. In the simulations with no skill differences, each year's aggregate wages equal \$176,000 (2000 males and 2000 females in each of 44 earning years earning $\$ 1$ per year). To generate the same annual wage flow for the simulations with skill differences, we normalize the two earnings arrays by a factor $\alpha$ such that the $\alpha^{*}\left(u^{\prime} M v+u^{\prime} F v\right)=176,000$, where $u$ and $v$ are unit vectors of lengths 2000 and 44 respectively. This yields normalized earnings arrays $M^{\prime}$ and $F^{\prime}$. The 2000 rows of $\mathrm{M}^{\prime}$ and $\mathrm{F}^{\prime}$ are then ranked and sorted according to the present value of earnings for each trajectory. The present values of earnings are calculated using a discount factor of 4 percent. These present values represent the skill level embodied in each of the 2000 male and 2000 female wage trajectories.

Each of the 2000 males (females) in a birth cohort is then assigned one of the 2000 male (female) rows at random. This assignment is done without replacement in order to ensure that each cohort that comes along has precisely the same distribution of earnings trajectories. In the case of assortative mating, we repeat the above assignment of skills, but then marry the highest skilled female with the highest skilled male, the second highest skilled female to the second highest skilled male, and so on, where skill is measured by the present value of lifetime earnings. In the case of inherited skills, we assign to each male agent the skill level of his father and to each female agent the skill 
level of her mother. In the case of inherited skills and assortative mating, males and females inherit their father's and mother's skills, respectively, and assortative mating proceeds based on this skill distribution.

$\underline{\text { Bequests and Inheritances }}$

When a married oldster dies, his or her spouse retains all the marital wealth. When a widowed oldster dies or if both spouses in a married couple die at the same time, the decedent(s') wealth is evenly divided among the children.

Initial Wealth Endowments and Length of the Simulations

To initiate a simulation, we give all adults at $t=0$ an endowment of wealth of 1 unit. We then run the model for enough years into the future until the distribution of wealth of 67 year-olds as well as the total amount of wealth in the economy stabilizes. Since the asymptotic wealth distribution as well as the total level of wealth are independent of the initial level and distribution of wealth, the fact that we start with this particular initial endowment of wealth doesn't alter our results. In practice, both the wealth distribution of 67 year-olds and the total level of wealth converge well before 150 years in each of our simulations. But to guarantee consistency across simulations, we ran each simulation for 150 years.

\section{Consumption and Saving Behavior}

Agents' expected utility are time-separable isoelastic functions of their own current and future consumption as well as that of their children through age 22 . Consider, 
as an example, the expected utility of a couple that is age 23 and will have two children. one when the couple is age 25 and the other when it is 28 :

$$
E U=\sum_{a=22}^{u=87} \beta^{u-22}\left(p_{h u} c_{h a}^{1-1 / \sigma}+p_{u a} c_{w u}^{1-1 ; \sigma}\right)+\delta \sum_{u=25}^{u=16} \beta^{u-22} c_{k 1 u}^{1-1 / \sigma}+\delta \sum_{u=28}^{u=49} \beta^{u-22} c_{k 2 u}^{1-1 / \sigma}
$$

In (1), the first summation considers the utility of each spouse from his or her own consumption at each possible age to which they could live. The second two summations consider the utility that the couple derives from the consumption of their two children. The terms $c_{h a}, c_{w a}, c_{k l a}$, and $c_{k 2 a}$ refer, respectively, to the consumption of the husband, wife, first child, and second child when the couple is age a. The term $\beta$ is the time-preference factor, $\sigma$ is the intertemporal elasticity of substitution, and $\delta$ is a childconsumption weighting factor. In our first set of simulations, we set the time preference rate (which equals $(1 / \beta)-1$ ) equal to the interest rate. We also set $\delta$ equal to .4 .

As $\sigma$ approaches zero, households become more and more reluctant (they become more and more concerned about) consuming smaller amounts in the future than they consume in the present. Since the inverse of $\sigma$ is the household's coefficient of relative risk aversion, a value of $\sigma$ close to zero translates into a coefficient of risk aversion close to infinity. In our simulations, we assume that $\sigma$ is very close to zero. '

Assuming that $\sigma$ is very close to zero simplifies enormously household consumption decisions. First this assumption in conjunction with the assumption of a time preference rate equal to the interest rate means that households seek to maintain the

\footnotetext{
${ }^{7}$ Hall (1988) reports that there is "... no strong evidence that the elasticity of intertemporal substitution is positive. Earlier findings of substantial positive elasticities are reversed when appropriate estimation
} 
same level of consumption over time for each spouse. Households also seek to maintain a constant level of consumption for their children, when they are children. Given the value of $\delta$. this child-consumption level equals 40 percent of the parental consumption level.

But most important, our assumption that $\sigma$ is very close to zero means that households only consider their safe resources in deciding how much to consume at each point in time. Thus households who expect to receive an inheritance, but don't know for sure that they'll get one (because all of their parents may to age 88 ), will ignore this potential source of future income in making their current consumption and saving decisions.

At each point in time, married households will calculate the number of years of remaining life, multiply this amount by 2 (to take into account the presence of both spouses) and then add to the resulting value .4 times the number of years of consumption of their children. This total number of effective adult consumption-years is then divided into the household's safe resources to determine consumption per effective adult. The household's safe resources consist of its wealth (which may reflect the receipt of past inheritances) plus the present value of its remaining lifetime labor earnings. Given the level of consumption per effective adult, it's straightforward to calculate total household consumption and subtract it from total household income to determine household saving.

We want to emphasize that inheritances affect consumption behavior, but only once they are received. There is no consumption out of potential future inheritances. Instead households, at each point in time, consider the worst-case scenario and formulate 
their consumption and saving plans accordingly. Were we to assume a positive value of $\sigma$ , households would take a gamble and consume more in the presence in anticipation of possibly inheriting in the future. But their decision as to how much to consume would be extraordinarily complex. The reason is that they would, at certain ages, have to take into account not simply their own resources, including their own wealth, but also that of their parents and their grandparents, assuming their grandparents are still alive. Take, for example, a 25 year-old couple with two sets of living parents and four sets of living grandparents. In deciding how much to consume the household has to consider its own current wealth level as well as the wealth levels of all six parental and grandparental households. Formally, the dynamic program that the household must solve to determine how much to consume involves up to seven state variables, namely all seven of these wealth levels. ${ }^{8}$ Unfortunately, solving dynamic programs with seven state variables appears to be beyond the capacity of current computers. ${ }^{9}$

\section{Data and Calibration}

The mortality probabilities used in the analysis are those released by the U.S. Social Security Administration for 1995. The interest rate (equal to the time preference rate) used in the simulations is 4 percent. As mentioned, the earnings and fertility matrices are derived from the CORSIM module. The CORSIM simulation modules for both are highly detailed. The earnings module was estimated from PSID data and

\footnotetext{
${ }^{8}$.We say "up to" because during years in which the household is age 66 and over, it has neither living parents nor living grandparents, and during years in which the household is age 44 through 65 , it has no living grandparents.
} 
includes separate logistic and regression equations for determining whether an agent works, whether a working agent works full or part year, how many weeks full-year or part-year workers work, how many hours per week full-year or part-year workers work, and how much full-year and part-year workers earn per hour. The intercept of each of these functions is adjusted to align the population-weighted labor supply behavior of CORSIM to national labor supply and earnings aggregates.

The fertility module includes separate logistic functions for 30 different subgroups of women estimated using data from the National Longitudinal Survey. The subgroups are distinguished by age, the presence of children, marital status, race, and work status. The regressors in the logits are age, duration of current marriage, earnings, family income, homeowner status, marital status, schooling status, work status, and duration since the birth of women's two youngest children. In producing the larger birth matrix from which we selected 2000 rows, we ran the CORSIM model from its start year of 1960 through 2000 . In so doing, we used the entire panoply of CORSIM modules to assign CORSIM agents the various socio-economic characteristics, such as work status, entering as regressors in the fertility logits.

\footnotetext{
${ }^{9}$ The fact that even supercomputers would have difficulty solving this problem in a reasonable amount of time raises the question of how mere mortals can actually deal with this complexity.
} 


\section{Findings}

Wealth Inequality in the SCF

For reference, we first report findings from the $1995 \mathrm{SCF}$ on the distribution of net worth among married households with household heads aged 60 to $69 .^{10}$ The richest 1, 5. and 10 percent of households hold $30.4,51.0$, and 62.5 percent of aggregate U.S. net worth. respectively. The Gini coefficient for this wealth distribution is 0.727 . These calculations indicate two things: first, the U.S. wealth distribution is highly unequal among married households whose household heads are of retirement age and second, the very rich account for a very sizeable fraction of total wealth.

Wealth Inequality Generated by Our Model

Table 3 begins to consider wealth inequality generated by our model. In this table, as well as Tables 4 through 6 , all households are assumed to earn a 4 percent real rate of return and the distribution of earnings is determined simply by the CORSIM data, i.e.. there is no adjustment for the upper tail of the earnings distribution.

Table 3 reports Gini coefficients of wealth and consumption distributions for households aged 66 . It also shows the flow of bequests as a share of labor income, and the flow of bequests left to children (as opposed to spouses) as a share of the economy's labor income. The odd-numbered rows report results without inheritances and the even

\footnotetext{
${ }^{10}$ The net worth calculation is based on computer code provided in the SCF documentation. The net worth percentiles are calculated using the final non-response-adjusted sample weights provided in the SCF.
} 
numbered rows those with inheritances; i.e., the odd-numbered simulations assume no mortality prior to age 88 .

The first point to make about Table 3 is that the flow of bequests is a significant fraction - roughly 9 percent -- of labor income for each of the simulations involving uncertain lifetimes. The flow of bequests to children, as opposed to spouses, is also significant - roughly 3 percent of labor income. Roughly speaking, the sizes of these flows correspond to estimates of bequest flows in the United States. For example, Auerbach, et. al. estimate the 1990 total U.S. bequest flow at $\$ 218$ billion, which amounts to about 6 percent of the wage flow in that year. Second, the flow of consumption is higher with inheritances than without. This is as expected since inheritances constitute an intergenerational redistribution from the old to the young. This raises the lifetime resources of each successive new generation, permitting it to consume at higher levels.

The first column of Table 3 indicates that the inclusion of uncertain lifetimes in the simulation has only a modest effect on wealth inequality. Leaving out skill differences and mortality, the Gini is just 0.05 . This Gini is non-zero because of differences across households in the number and timing of their children. These differences influence the amounts that households consume when young and, thus, the amounts of wealth they bring into old age. Although the addition of uncertain lifetimes raises the Gini coefficient by almost two thirds, to 0.08 , this is still a very small value and suggests that, by themselves, inheritances arising from random death are not a major source of wealth inequality across members of the same cohort.

In contrast, Table 3 shows that skill differences are a major force behind wealth inequality in our model. With inheritances, the introduction of skill differences increases 
the wealth Gini from 0.08 to 0.44 (compare rows 2 and 4). Under our assumptions and parameterization, fertility differences, inheritances, and skill differences jointly explain more than 60 percent of the intragenerational inequality observed in the SCF data, with skill differences being the predominant factor.

The inclusion of marital sorting by skill further increases the wealth Gini coefficient to 0.53 (Table 3, row 6). This effect is significant, but not huge. The reason is that the rate of increase in skill levels for each skill-rank increment is small for the first 1900. Hence, marital sorting by skill class does not imply pairing individuals with very different skill levels relative to marrying them at random. This effect accounts for a further 13 percent of the Gini observed in the SCF data. Adding inheritance of skills only marginally increases the Gini coefficient on wealth to 0.57 (Table 3, row 10). Thus, inheritance of skills contributes only marginally to intragenerational wealth inequality.

Although uncertainty in dates of death raises wealth inequality slightly in the absence of skill differences, it does the opposite in the more realistic case that skill differences exist. As rows 3 through 10 in Table 3 indicate, this is true whether or not couples sort themselves in the marriage market based on skills or whether skills are inherited. Under each of these assumptions, the Gini coefficient is somewhat smaller with uncertain lifetimes than without; that is, inheritances reduce, rather than raise, wealth inequality. This result is not surprising. Because only a few households in each birth cohort have very high skills, very large bequests are likely to go to children with skill levels lower than their parents' skill level. This has a slight equalizing effect on the distribution of wealth at retirement. 
Note that the Gini values for consumption at retirement are the same as those for wealth. This is because for a given number of children, lifetime resources, consumption, and wealth at retirement are all strictly proportional in all of the simulations reported in Table 3. Table 4 shows wealth held by households in the top $\mathrm{x}$ percentiles for selected values of $x$. Consistent with the results of Table 3, wealth held by richer households is much larger when skill differences are present. In the presence of inheritances, for example, the share of wealth held by the richest 5 percent of households increases by more than a factor of three (compare rows 2 and 4 in Table 4). With inheritances and skill differences, the fractions of wealth held by the richest 1,5 , and 10 percent of households are all higher when marital sorting by skill is introduced (compare rows 6 and 4). They are not very different when children inherit skills from their parents compared to the case that skills are assigned at random to members of each cohort (compare rows 8 and 4). The wealth distributions reported thus far exhibit much less inequality than found in the SCF. In each of the rows in Table 4, the shares of wealth held by the richest 1,5 , and 10 percent of households are much smaller compared to those reported in Table 2. 
Introducing Progressive Income Taxation and Social Security $\underline{ }$

We introduce the annuitization of retirement savings via social security by assuming that 15.3 percent (the OASDHI Social Security and Medicare payroll tax rate) of each year's labor income, up to a maximum taxable limit (calibrated to correspond to the U.S. Social Security System's taxable limit), is accumulated at a 4 percent interest rate and converted, at retirement, into an actuarially unfair annuity. Caldwell, et. al. (1999) estimate that on average, 67 cents of every dollar paid in OASI payroll taxes represents a pure tax. That is, the present value of Social Security OASI benefits at retirement equals the accumulated value of only 33 percent of OASI payroll taxes paid during the working lifetime. Unfortunately, similar "money's worth" calculations are not available for Medicare of the Disability Insurance program. We assume only 30 percent of each person's payroll taxes are converted into an annuity, with the rest representing a pure tax.

Adding social security to the model raises the possibility that households for whom consumption per adult is small relative to annuity income per adult will wish to borrow against their benefits. To prevent households from leaving negative bequests, we

\footnotetext{
"Introducing progressive income taxation by itself does not qualitatively change the results reported in Table 3. As expected, wealth inequality at retirement is lower in all cases simply because households with higher income face higher average tax rates. In addition, consumption inequality is lower than wealth inequality at retirement because greater wealth cannot be converted into a proportionally greater consumption stream at retirement: The asset income generated along the way is taxed at higher average income tax rates. Table 3 's result that inheritances reduce rather than increase wealth inequality at retirement is not overtumed by the introduction of progressive income taxes alone. However, the impact of progressive income taxation in the presence of social security is qualitively different. Apparently, progressive income taxation in the presence of social security acts like higher levels of social security benefits in limiting the wealth accumulation of the poor and the middle class and disenfranchising their children with respect to inheritances. This causes a reduction in the flow of bequests as a share of labor income. On the other hand, the differentially higher burden that progressive income taxation imposes on high income households, limits their wealth accumulation as well. The net impact is this rather minor decline in wealth inequality.
} 
subject such households to a borrowing constraint at retirement. That is, net borrowing is permitted prior to retirement but the liability must be extinguished to leave the household with exactly zero net worth at retirement.

In each case, introducing annuitization considerably increases wealth inequality. For example, Table 5 shows that when all the factors are present, the introduction of social security increases the Gini coefficient from 0.57 to 0.71 (compare rows 10 in Tables 3 and 5)-very close to the 0.73 value of the SCF wealth distribution. Wealth inequality is increased because a sizable fraction of low earning households now arrive at retirement with low or zero wealth. In contrast, richer households--for whom the annuity is very small relative to consumption per capita--accumulate roughly the same amount of wealth that they would have accumulated in the absence of social security.

The introduction of social security changes qualitatively the impact of inheritances on intragenerational wealth inequality: Now, inheritances increase wealth inequality. For example, the Gini coefficients for the experiments of rows 9 and 10 become 0.65 and 0.71 respectively. The explanation here is that the availability of annuities makes the distribution of bequeathable wealth much less equal and perpetuates wealth inequality across extended families. High earning parents who accumulate positive wealth through retirement will bequeath a substantial sum if they die early. The receipt of inheritances by their children causes them to arrive at retirement with substantial wealth. Hence, they may, in turn, bequeath substantial wealth to their children and so on.

This sequence of bequests and accumulation by rich households stands in sharp contrast to that of poor households. The latter do not bequeath much wealth to their 
children. Indeed, those who are borrowing constrained arrive at retirement with zero wealth, live entirely off of social security during retirement, and make no bequests when they die. As a result, their children arrive at retirement with less wealth than otherwise. The annuitization of lifetime resources makes the distribution of inheritances much more unequal and increases persistence in the incidence of bequests across bequeathing and non-bequeathing households. Consequently, the inheritance process reinforces rather than reduces wealth inequality at retirement. Social security's role in reducing bequests through its provision of annuities is also evident in its impact on the ratios of aggregate and cross generational bequests to aggregate labor income: Both ratios fall to about 30 percent of their values in Table 3.

Turn next to Table 6's wealth distributions. In the row-10 simulation, the top 1 , 5 , and 10 percent of 66-year-old households hold $22.7,51.0$, and 64.3 percent of aggregate wealth, respectively. These figures are much closer to the SCF wealth distribution than those in Table 4. Almost all of the increase in the concentration of wealth arises from the introduction of social security. That said, this simulation is not particularly realistic given that it assumes perfect marital sorting and perfect inheritance of skills.

Sensitivity to the Assumed Degree of Actuarial Fairness of Social Security Benefits

The simulation findings turn out to be highly sensitive to the degree to which U.S. Social Security benefits are assumed to be fair. If we assume that Social Security (including Medicare) pays benefits that equal, in present value, 35 percent of the present value of contributed taxes, the wealth Gini for the row-10 case of Table 7 increases from 
0.71 to 0.80 . Moreover, the top 1,5 , and 10 percent of 66 year-old households now hold $27.5,60.6$, and 75.3 percent of aggregate wealth, making the upper tail of the wealth distribution noticeably more skewed than that found in the SCF data (see Table 2).

\section{Sensitivity to the Assumed Interest Rate}

We also ran our Table 5, row-10 simulation assuming a 6 percent real rate of interest (and a 6 percent time preference rate). In so doing, we left unchanged the level of social security benefits provided each worker. Interestingly, neither the Gini coefficient nor the upper tail of the wealth distribution is much affected by the choice of interest rate. The Gini coefficient for this run is 0.71 , and the top 1,5 , and 10 percent of wealth holders account for $21.6,50.5,64.8$ percent of total wealth. These values are almost identical to those reported in rows 10 of Tables 5 and 6 . The explanation for this is that a higher interest rate, by lowering the price of future consumption, permits households to consume more at every age. This is true notwithstanding the reduction in the present value of their human wealth and social security benefits due to the higher interest rate. Although planned pre- and post-retirement consumption is higher, the assets at retirement needed to finance post-retirement consumption are not necessarily larger-again because of the lower price of post-retirement consumption. Hence, a higher interest rate materially alters neither household assets at retirement nor the distribution of those assets.

\section{$\underline{\text { Toward a More Realistic Simulation }}$}

The previous simulations invoked extreme assumptions with respect to marital sorting, the inheritance of skills, and the uniformity across households of rates of return. These assumptions were made to clarify the nature of the effects of these and other 
factors on bequests and wealth inequality. In the remainder of the paper, we show how more realistic assumptions alter our findings. In this regard, we also consider a lower rate of time preference and what appears to be a more realistic upper-tail of the distribution of lifetime labor earnings.

$\underline{\text { Imperfect Marital Sorting and Imperfect Inheritablity of Skills }}$

There is little solid evidence to use to calibrate the degree of marital sorting and inheritability of skills. But what evidence exists, together with our priors, leads us to consider 0.5 rank correlation coefficients between the lifetime earnings of husbands and wives. Solon (1992) and Solon and Zimmerman (1992) suggest a value of 0.5 for the inheritability coefficient (the correlation between parents' and childrens' earnings). But this value generates what appears to us to be a bit too much wealth mobility. Consequently, we choose a value of 0.7 for our final simulations. ${ }^{12}$ This decision does not materially alter simulated wealth concentration at retirement.

Including Interest Rate Heterogeneity

Different individual face different rates of return in capital markets. To incorporate rate-of-return heterogeneity, we use data on the portfolio holdings of households from the 1995 SCF. We classify household reported assets into several categories, assign a rate of return to each category, and compute each household's

\footnotetext{
12 Matching spouses by skill levels (or associating child-parent skill levels) to deliver a correlation coefficient close to the selected value in each year of the simulation is achieved by taking a linear combination of the two extreme cases of perfect matching and random matching of individuals by skill.
} 
portfolio-weighted rate of return. ${ }^{13}$ The weighted frequency of households for rates of return ranging from zero to $10+$ percent in steps of 0.5 percent is used to randomly allocate the average rate of return within each step to households in the simulation. Households are assumed to earn their assigned rate of return in each year of their lives and there is zero correlation between rates of return earned by parent and child households.

\section{Calibrating the Rate of Time Preference}

In addition to including unrealistic assumptions about assortative mating and inheritance of skills, the simulation in row 10 of Table 5 produces two ratios that are unrealistic - one is a 1.9 ratio of aggregate wealth to aggregate labor income, the other is a .025 ratio of the flow of bequests to aggregate labor income. In the U.S, these two ratios are roughly 6 and .06 , respectively. To produce a more realistic set of results, we

\footnotetext{
${ }^{13}$ The asset categories are liquid assets, government bonds, private bonds and bond mutual fund shares, stocks and stock mutual funds, real estate, and other non-financial assets. Liability categories include mortgages and real estate debt and other debt. In forming a weighted average rate of return on each household 's portfolio, we used the absolute value of liabilities. For liquid assets we assumed the geometric average annual real rate of return (0.68 percent) on U.S. Treasury bills during the period 1926-97. For government bonds we use the geometric average annual real rate of return on long and intermediate term government bonds between 1926 and 1997 (2.09 percent). For private bonds and bond mutual funds we use the geometric average rate of return on long-term corporate bonds between 1926 and 1997 (2.52 percent). For stocks and stock mutual funds, we use the weighted average of real rates of return on large and small company stocks ( 8.00 percent). The weights for the two stock market returns were obtained from analysts at the Wilshire 5000 company. The source for the aforementioned average rates of return is the 1998 Yearbook published by Ibbotson Associates. The average rates of interest on mortgages and other real estate debt was constructed using date from Case and Shiller (1990) who report annualized excess returns (excess over the 3-month T-bill return) on home-purchases for each quarter between 1971 and 1986 in four large U.S. metropolitan areas. We computed the total returns by adding the annualized real T-bill return for each quarter, calculated the geometric mean over the period of the study, and averaged the rates of return over the four metropolitan areas. This procedure yields a real rate of return of 0.45 percent. Finally the rate of retum for mortgage and real estate debt was calculated as the geometric average nominal mortgage rate between 1973 and 1997 divided by the geometric average rate of inflation over the same period. This yielded 3.91 percent. The average real rate on other debt was assumed to be 13.54 percent the rate applicable for 1995-obtained from the Statistical Abstract for the United States, 1998, Table 820.
} 
modified our assumption of zero life-cycle growth in consumption per adult equivalent, apart from that arising from liquidity constraints and the receipt of inheritances. Specifically, we assumed that (apart from the aforementioned caveats), consumption per equivalent adult rises at 1.5 percent per year through age 66 . This produces a longitudinal age-consumption profile that accords much more closely with the actual U.S. profile. We refer below to this adjustment in terms of a reduction in the time-preference rate through the age of retirement.

Adjusting for the Upper Tail of the Distribution of Lifetime Earnings

As mentioned, the econometric functions comprising CORSIM's earnings module were estimated from the PSID. Although the PSID has many advantages, sampling high income and high wealth households is not one of them. Consequently, CORSIM's earnings module appears to considerably understate the degree of skewness in the actual distribution of lifetime earnings. For example, the present value of earnings of the highest earning male in CORSIM is only 4.4 times as large as that of the male in the $95^{\text {th }}$ percentile. For females the corresponding earnings multiple is 12.7. Across the 4000 males and females, the present value of earnings has a Gini coefficient of 0.129 . In the SCF however, the earnings multiple is 65.3 for the highest earning male and 44.7 for the highest earning female. In order to incorporate a more realistic earnings distribution in the simulation we replace the top 5 percent of the CORSIM earnings distribution with 
that obtained from the $1995 \mathrm{SCF} .^{14}$ Despite the adjustment, the Gini for the present value of earnings across the 4000 individuals increases only slightly to 0.133 .

$\underline{\text { Results Based on More Realistic Assumptions }}$

Tables 7 and 8 show how the more realistic assumptions just described alter the results. The first row of each table begins with the respective row-10 results of Tables 5 and 6. Rows $2,3,4,5$, and 6 in each table show the impact of deviating from the previous row-10 assumptions by respectively incorporating partial marital sorting, partial inheritance of skills, rate of return heterogeneity, a lower time-preference rate through retirement, and the top earnings tail adjustment. The last row, row 7 , in each table simultaneously invokes all five of the new assumptions.

Although we ran the simulations involving the top earnings tail adjustment out for over 200 years, the distribution of wealth fluctuated from year to year to a much greater degree than was the case for all the other simulations. For example, in the last 15 years, the Gini coefficient for the run with all five new assumptions fluctuated between .624 and .729 and the wealth share of the richest 1 percent fluctuated between 24.7 percent and 41.1 percent. To deal with this issue, we report in rows 6 and 7 the average values of variables over the last 15 years of the simulations.

\footnotetext{
${ }^{14}$ This is accomplished by re-scaling the CORSIM longitudinal profiles for the top 100 skill ranks for both males and females. The CORSIM skill ranks are based on present values of earnings of the longitudinal earnings profiles calculated using a 4 percent rate of discount. The 1995 SCF skill ranks are based on the wage and salary levels of randomly selected samples of 2000 males and 2000 females age 35 to 45 . We used this age range because we felt that the distribution of annual earnings would better approximate the distribution of lifetime earnings at these ages than at other ages. First, the skill levels for both the CORSIM and the SCF skill distributions are normalized to make the skill level at the $95^{\text {th }}$ percentile equal to unity in each. Second, each CORSIM longitudinal skill profile corresponding to the 100 ranks higher than the $95^{\text {th }}$ percentile are re-scaled by the ratio of the SCF normalized skill level to the CORSIM
} 
The major new messages of Tables 7 and 8 are the importance of both the rate of time preference and the critical importance of the shape of the top tail of the lifetime earnings distribution to wealth inequality. As row-5 shows, a lower rate of time preference prior to retirement age reduces wealth concentration. The top 1 percent of wealth holders now hold only 16.3 percent of total wealth, compared to 22.6 percent when there is no desired growth in consumption per adult equivalent. This makes sense. The lower time-preference rate produces relatively more wealth accumulation at the bottom end of the wealth distribution, which is otherwise almost exclusively dependent on social security benefits in retirement. Although it makes wealth concentration too low, this change in assumptions dramatically raises the economy's ratios of wealth to labor income and bequests to labor income. The two ratios are now 5.4 and .05 .

Adding just the top-tail adjustment to the distribution of lifetime earnings considerably increases the degree of wealth inequality as measured by the share of wealth of the top 1 percent. Now the top 1 percent have 39.7 percent of total wealth. In considering this result, it's important to bear in mind that our top-tail earnings adjustment is crude for two reasons. First, the SCF doesn't provide information about lifetime earnings. Second, try as it may, the SCF is unlikely to be sampling the Bill Gates of this world, whose annual labor earnings run into the hundreds of millions if not billions, thereby understating earnings as well as wealth inequality.

As the row-7 results show, including the top tail adjustment with all the modifications in the other assumptions generates wealth shares for the top 1,5 , and 10

normalized skill level for that skill rank. Finally, the entire set of 2000 CORSIM longitudinal profiles are re-normalized to deliver a total wage flow of $\$ 176,000$ in each period of the simulation. 
percent of 32.8 percent, 49.4 percent, and 58.8 percent. These figures are very close to the corresponding SCF values of 30.4 percent. 51.0 percent, and 62.5 percent. Thus, based on the combined set of more realistic assumptions, our model appears capable of reproducing actual U.S. wealth inequality. Furthermore, under these assumptions, the model generates realistic ratios of wealth to labor income and bequests to labor income. The respective values of 6.0 and .055 are quite close to their empirical counterparts.

\section{Intergenerational Wealth Mobility}

This section considers the degree of intergenerational wealth mobility arising in our final simulation (the last row of Table 7 ). ${ }^{15}$ Table 9 presents a wealth mobility matrix in which the rows represent parent-household wealth positions and the columns indicate child-household wealth positions, both at age 66 . The numbers in each row show the probability (in percentage terms) of the child being in the column wealth range given the parent wealth range represented by that row: ${ }^{16}$ Consider a wealth value of 18 in the table. This is the cutoff value for the top 20 percent of wealth holders. According to the table, almost one half of children whose parents are in the top 20 percent of wealth holders at age 66 end up in the top 20 percent of wealth holders when they themselves reach age 66 .

${ }^{15}$ Transition matrices for other simulations are available from the authors upon request.

${ }^{16}$ Each child household has two parent households. Hence, in forming the probabilities in the transition matrices of Table 9, we count each child household twice. First we pair the child's household wealth at age 66 with the male spouse's parent household wealth at age 66 and enter this pairing in the appropriate cell of the transition matrix. Next, we pair the child's household wealth with the female spouse's parent household wealth at age 66 and enter this pairing again in the appropriate cell of the transition matrix. These entries are aggregated for all child households after the $132^{\text {nd }}$ year of the simulation. Thus, the transition probabilities reflect both parent household wealth positions. The probabilities reported are those of the child household's wealth position (column) conditional of the parent household's wealth position (row). 
This result is in rough agreement with the evidence in Wedgwood (1929), Harbury and Hitchens (1979) and Menchick (1979). ${ }^{17}$

Next, consider parents in the poorest group, whose wealth ranges from 0 to 6 . The children of these parents have a 47.4 percent chance of finding themselves in the same wealth group when they reach age 66 . And they have a similar likelihood of being in the one of the next two higher wealth groups. So 95 percent of these children will end up poor as well. Indeed, the chance that these children will end up in one of the top 5 wealth ranges is only 0.5 percent. $^{18}$ For the children of the richest parents, this chance is 22 percent. ${ }^{19}$ These results notwithstanding, Table 9 shows that wealth mobility is fairly high from some perspectives. Take the richest parents. The probability that their children will be end up at age 66 in one of the five lowest poorest wealth ranges is 52 percent.

Wealth mobility is highly sensitive to our assumed degree of inheritability of skills. And for high degree of skill inheritance, wealth mobility is substantially reduced by assuming higher degrees of assortative mating. For example, the probability that the children of the super rich end up super rich themselves rises from 15.9 percent to 49.3 percent if the correlation coefficient of inheritability is increased from 0.7 to 1.0. And holding this coefficient at 0.7 , this probability rises from 15.9 percent to 20.9 percent if the correlation coefficient of assortative mating is raised from 0.5 to 1.0 .

\footnotetext{
${ }^{17}$ Note, however, that these studies do not control for the age at which wealth of parents and children is observed and it is unclear to which segments of the wealth distribution their samples correspond.

${ }^{18}$ This number does not correspond to the sum of those reported in the table because of rounding.

${ }^{19}$ The correlation coefficient of parental and child age- 66 wealth in this final run is 10 percent. This is much smaller than the correlation reported by Menchik, but, as argued above, Menchik's is correlating wealth at different ages and doing so on a restricted subset of the population.
} 


\section{Caveats and Conclusion}

Because of their random nature and receipt by a lucky few, many people intuitively believe that inheritances cause considerably greater wealth inequality among members of the same cohort. Surprising as it may seem, this is not necessarily the case. Because the process underlying inheritances is largely unrelated to the earnings differences that are the key determinant of life cycle wealth accumulation, inheritances can be wealth-equalizing.

This paper develops a large-scale, life-cycle simulation model to explore the role of inheritances and other factors in generating wealth inequality. The model includes uncertain longevity, fertility differences, skill differences, assortative mating, inherited skills, heterogeneous rates of return, annuitization via a social security system, and progressive income taxation. We find that skill differences, the annuitization of retirement savings, assortative mating, and the skewness of the upper tail of the earnings distribution, are the major factors underlying intragenerational wealth inequality. In addition, the inheritance of bequests is an important contributor to wealth inequality, but only in the presence of social security; That is, without social security, bequests actually reduce wealth inequality, albeit to a minor degree. Interestingly, the inheritance of skills from one's parents does not much matter for wealth inequality. Most of wealth inequality stems from earnings inequality, and how members of a particular generation came to have their unequal earnings doesn't change the fact that their levels of accumulated wealth will differ. Another minor factor with respect to the wealth distribution is progressive income taxation. 
All told, the factors examined in this paper are capable of reproducing observed U.S. wealth inequality among married couples at retirement. What we believe to be our most realistic simulation produces a Gini coefficient of 0.65 - not far from the .73 Gini coefficient found in the SCF. This same simulation leaves the top 1,5 , and 10 percent of wealth holders holding 31.6, 47.0, and 55.9 percent of aggregate wealth, respectively. These wealth shares are quite close to the corresponding 1995 SCF values for married couples in their 60 s of $30.4,51.0$ and 62.5 percent.

We also learned that inheritance of skills and its interaction with marital sorting, rather than inheritance of wealth, are the main factors in limiting intergenerational mobility across wealth levels. Under the most realistic calibration of the simulation, the probability is 15.9 percent that children of the super rich will themselves be super rich.

We've taken our model through a number of paces, but left others for future research. These include adding heterogeneous saving preferences (i.e., differences in time preference rates), income- or wealth-correlated mortality probabilities, different ages of first marriage, changes in marital status, and a more detailed set of fiscal institutions as in the impressive study by Hubbard, Skinner, and Zeldes (1994).20

${ }^{20}$ Including a distribution of time preference rates would generate even greater wealth inequality if the propensity to save were correlated with the level of lifetime earnings or inherited wealth. On the other hand, if saving behavior were uncorrelated with economic resources, the dispersion in time preference rates would produce a larger dispersion in wealth at retirement, but not necessarily larger measures of wealth concentration. One could also consider preferences espoused by Carroll (1998) in which people accumulate wealth for the sake of power and status, rather than to finance consumption. Incorporating earnings uncertainty (as in Hubbard, Skinner, and Zeldes, 1994), health-care expenditure uncertainty, and rate of return uncertainty are additional key elements to consider in future work. Incorporating higher survival probabilities for those with greater economic resources (more money buys better health care) would reduce the model's wealth inequality and immobility. The reason is that the richest elderly would live the longest and would, as a group, spend down a larger fraction of their wealth before they died. This, of course, means reduced inheritances for the children of the rich, making the wealth holding of 
Whatever the true merit in our preference and other assumptions, this paper has, at a minimum, introduced some new technology for studying key factors underlying wealth inequality. Its rather surprising findings - that intentional bequests are not needed to generate either a very high degree of wealth concentration or a realistic stock of wealth relative to the size of the economy, that inheritances, absent social security, can equalize the wealth distribution, that social security is likely to make inheritances much more unequal, and that the skewness of the distribution plays a pivot role in wealth inequality may bring us somewhat closer to understanding the key factors underlying the actual U.S. distribution of wealth.

these children and their contemporaries less concentrated and less correlated with that of their parents. The forgoing argument postulates causality from resources to longevity. However, the opposite possibility cannot be ruled out. If longevity affects saving behavior, the wealth distribution across each retiring cohort may well exhibit greater inequality as longer lived households saved more to finance a lengthier retirement. 


\section{References}

Abel, A., Kotlikoff, L.J., 1994. "Intergenerational Altruism and the Effectiveness of Fiscal Policy: New Tests Based on Cohort Data," in Savings and Bequests. Ann Arbor, Michigan: University of Michigan Press.

Altonji, J.G., Hayashi, F., Kotlikoff, L.J., 1992. "Is the Extended Family Altruistically Linked? Direct Tests Using Micro Data," The American Economic Review, December.

Altonji, J.G., Hayashi, F., Kotlikoff, L.J., 1997. 'Parental Altruism and Inter Vivos Transfers: Theory and Evidence. 'Journal of Political Economy 105(6), 1121-66.

Atkinson, A.B., 1980. "Inheritance and the Redistribution of Wealth," in G.M. Heal and Hughes, eds., Public Policy and the Tax System, London: Allen and Urwin.

Atkinson, A.B., 1971. "The Distribution of Wealth and the Individual Life Cycle," Oxford Economic Papers 23, 239-54.

Atkinson, A.B., Harrison, A.J., 1978. Distribution of Personal Wealth in Britain, Cambridge, England: Cambridge University Press.

Atkinson, A.B., Stiglitz, J., 1980. 'Lectures in Public Economics', McGraw-Hill, Singapore.

Auerbach, A.J., Gokhale, J., Kotlikoff, L.J., Sabelhaus, J., and Weil, D., 1999. "The Annuitization of Americans' Resources - A Cohort Analysis," mimeo.

Becker, G.S., Tomes, N., 1986. 'Human Capital and the Rise and Fall of Families.' Journal of Labor Economics 4(3), Part II, S1-39.

Becker, G.S. and Nigel, T., 1979. 'An Equilibrium Theory of the Distribution of Income and Intergenerational Mobility. 'Journal of Political Economy 87(6), 1153-89.

Blinder, A.S., 1973. 'A Model of Inherited Wealth. 'Quarterly Journal of Economics $87(4), 608-26$.

Blinder, A.S., 1974. Toward An Economic Theory of Income Distribution, Cambridge, MA, MIT Press.

Blinder, A. S., 1976. 'Inequality and Mobility in the Distribution of Wealth,' Kyklos 29, 607-38.

Boskin, M.J., Kotlikoff, L.J., 1985, "Public Debt and U.S. Saving: A New Test of the Neutrality Hypothesis," Carnegie-Rochester Conference Series on Public Policy, Autumn. 
Caldwell, S., Favreault, M., Gantman. A., Gokhale, J., Johnson, T., Kotlikoff, L.J., 1999, "Social Security's Treatment of Postwar Americans," forthcoming in Tax Policy and the Economy, NBER volume, 13, MIT Press.

Case, Karl E., and Shiller, Robert J. "Forecasting Prices and Excess Returns in the Housing Market," AREUEA Journal, Vol. 18, No. 3, 1990, pp. 253-73.

Davies, J.B., Kuhn, P.J., 1991. 'A Dynamic Model of Redistribution, Inheritance, and Inequality. 'Canadian Journal of Economics 24(2), 324-44.

Davies, J.B., 1982. "The Relative Impact of Inheritance and Other Factors on Economic Inequality.' Quarterly Journal of Economics 97(3), 471-98.

Davies, J.B. and Shurrocks, A., 1971. "Assessing the Quantitative of Inheritance in the Distribution of Wealth," Oxford Economic Papers 30(1), 239-254.

Flemming, J.S., 1976, "On the Assessment of the Inequality of Wealth," in Selected Evidence Submitted to the Royal Commission: Report No. 1, Initial Report of the Standing Reference (Royal Commission on the Distribution of Income and Wealth, HMSO, London), 34-70.

Flemming, J.S., 1979. "The Effects of Earnings Inequality, Imperfect Capital Markets, and Dynastic Altruism on the Distribution of Wealth in Life Cycle Models," Economica 46, 363-80.

Gokhale, J., Kotlikoff, L.J., Sabelhaus, J., 1996, "Understanding the Postwar Decline in United States Saving: A Cohort Analysis," The Brookings Papers on Economic Activity.

Harbury, C.D. and D.M.W.N. Hitchens, 1979. Inheritance and Wealth Inequality in Britain. London. George Allen and Unwin.

Hubbard, R.G., Skinner, J.S., Zeldes, S.P, 1994. "The Importance of Precautionary Motives for Explaining Individual and Aggregate Saving," in Meltzer, A.H., Plosser, C.I., (Eds), The Carnegie-Rochester Conference Series on Public Policy 40, 59-126.

Huggett, M., 1996. "Wealth Distribution in Life Cycle Economies." The Journal of Monetary Economics 38, 469-94.

Hurd, M.D., 1990. "Research on the Elderly: Economic Status, Retirement and Consumption \& Saving". Journal of Economic Literature 28, 565-637. 
Hurd, M.D., 1992. "Measuring the Bequest Motive: the Effect of Children on Saving by the Elderly in the United States". in Savings and Bequests. Ed. T. Tachibanaki. University of Michagan Press, 111-136.

Laitner. J., Juster, F. T., 1996. 'New Evidence on Altruism: A Study of TIAA-CREF Retirees. 'American Economic Review 86(4), 893-908.

Laitner. J., 1979a. 'Household Bequests, Perfect Expectations, and the National Distribution of Wealth. 'Econometrica 47(5), 1175-93.

Laitner, J., 1979b. 'Household Bequest Behaviour and the National Distribution of Wealth. 'Review of Economic Studies 46(3), 467-83.

Loury, G., 1981. "Intergenerational Transfers and the Distribution of Earnings". Econometrica 49(4). Pp 843-67.

Meade. J.E. (1964). Efficiency, Equality, and the Ownership of Property, London: Allen \& Urwin.

Meade. J.E., (1966). "Life-cycle Savings, Inheritance and Economic Growth". Review of Economic Studies. Vol 33. Pp 61-78.

Meade. J.E. (1976). The Just Economy: George Allen \& Unwin, London.

Menchik. P., 1979. "Intergeneration Transmission of Inequality: An Empirical Study of Wealth Mobility" Economica 46:349-362.

Miles. D., 1997. "Demographics and Saving: Can we Reconcile the Evidence". Paper presented to National Institute Conference on the Macroeconomics of Inequality. Churchill College, Cambridge.

Oulton, N., 1976. "Inheritance and the Distribution of Wealth," Oxford Economic Papers 28, 86-101.

Pryor, F., 1973. "Simulation of the Impact of Social and Economic Institutions on the Size Distribution of Income and Wealth,"American Economic Review 63, 50-72.

Solon, G., 1992. 'Intergenerational Income Mobility in the United States. 'American Economic Review 82(3), 393-408.

Solon, G., Zimmerman, D.J., 1992. 'Regression toward Mediocrity in Economic Stature. 'American Economic Review 82(3), 409-29. 
Stiglitz. J.E., 1969. 'Distribution of Income and Wealth among Individuals. 'Econometrica 37(3), 382-97.

Tomes, N., 1981. 'The Family, Inheritance, and the Intergenerational Transmission of Inequality. 'Journal of Political Economy 89(5), 928-58.

Wilhelm, Mark O., 1996. 'Bequest Behavior and the Effect of Heirs' Earnings: Testing the Altruistic Model of Bequests. 'American Economic Review, 86(4), 874-92.

Wilhelm. M.O., 1997. 'Inheritance, Steady-State Consumption Inequality, and the Lifetime Earnings Process. 'Manchester School of Economic and Social Studies, Vol. 65(4), 466-76.

Wolfson, M., 1977. "The Causes of Inequality in the Distribution of Wealth: A Simulation Analysis," Ph.D. thesis, Cambridge University.

Wolfson, M.,1979. "The Bequest Process and Causes of Inequality in the Distribution of Wealth." In J.D. Smith (Ed), Modelling the Intergenerational Transmission of Wealth. New York: NBER. 
</ref_section> 


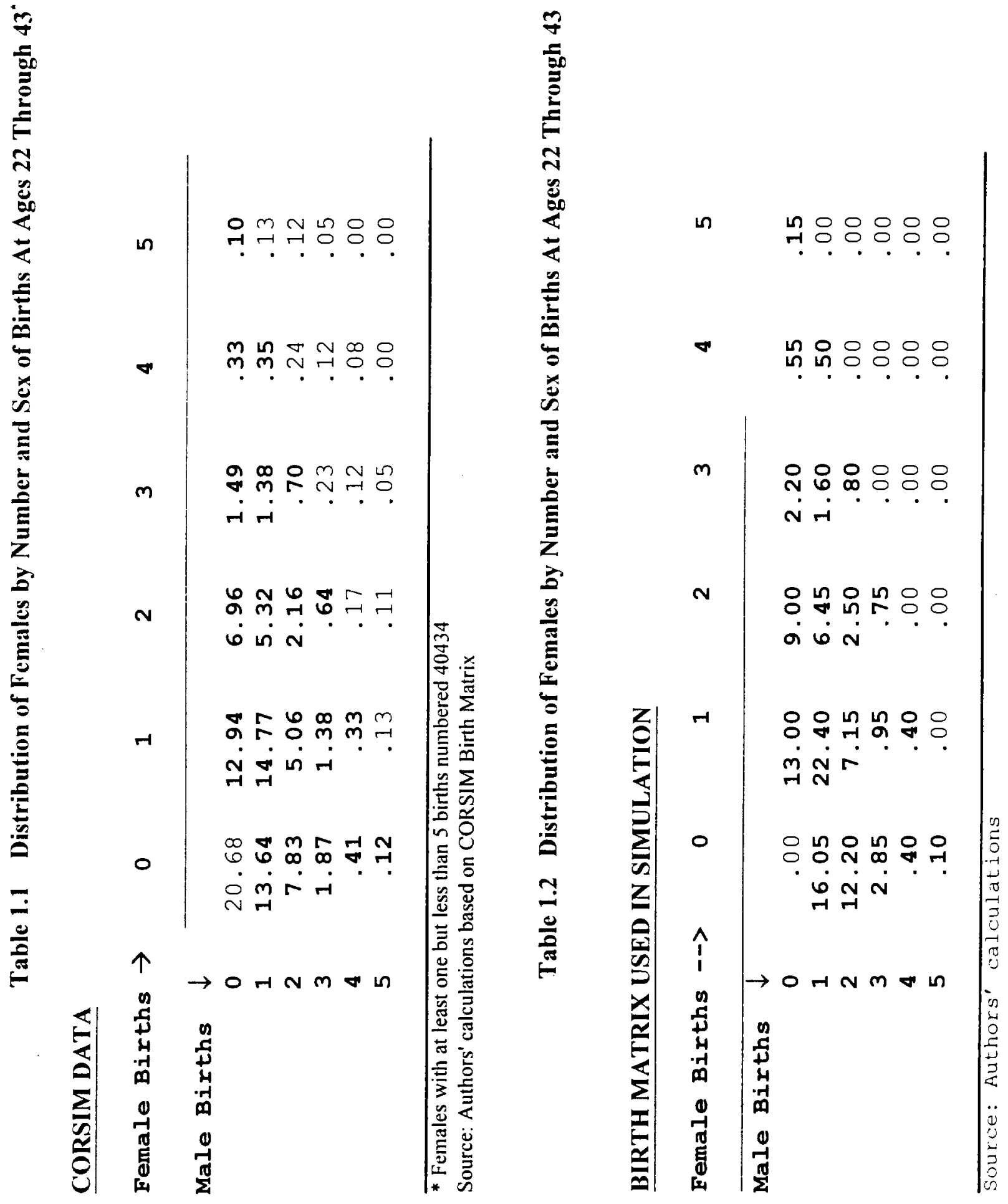




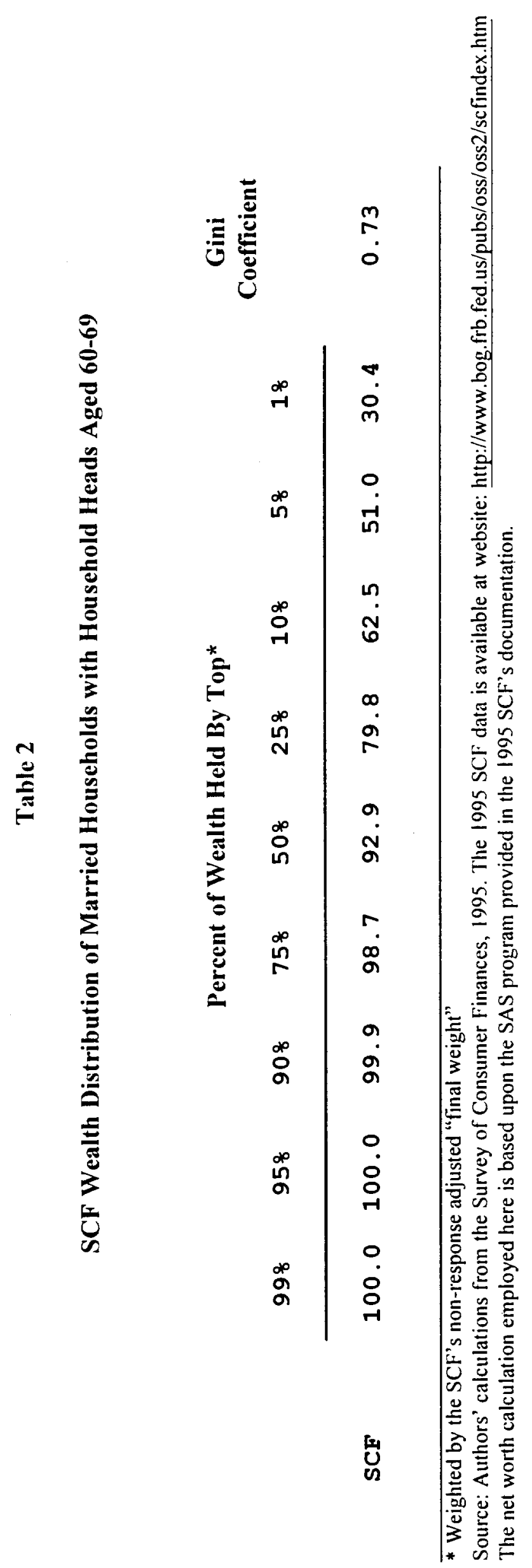




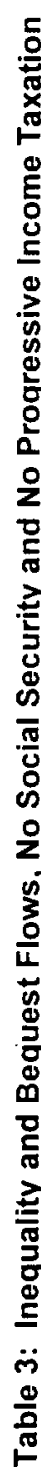

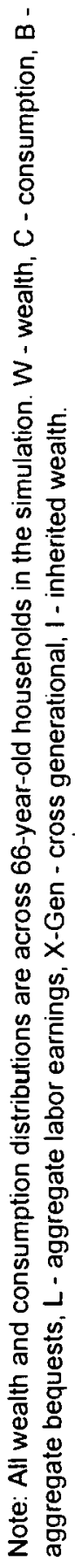

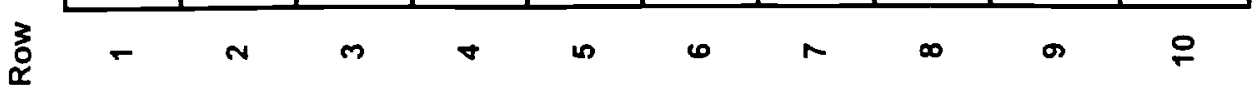




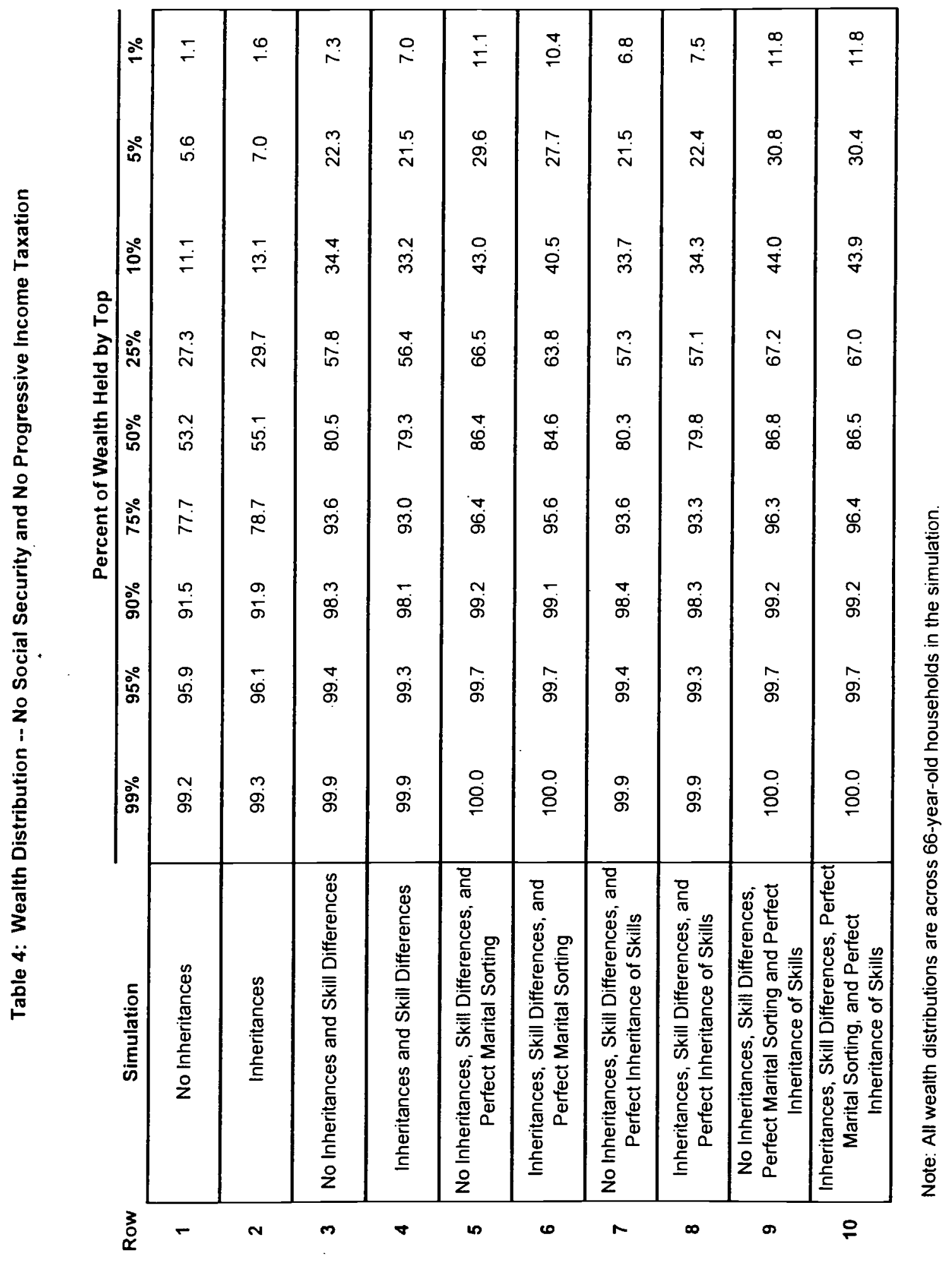




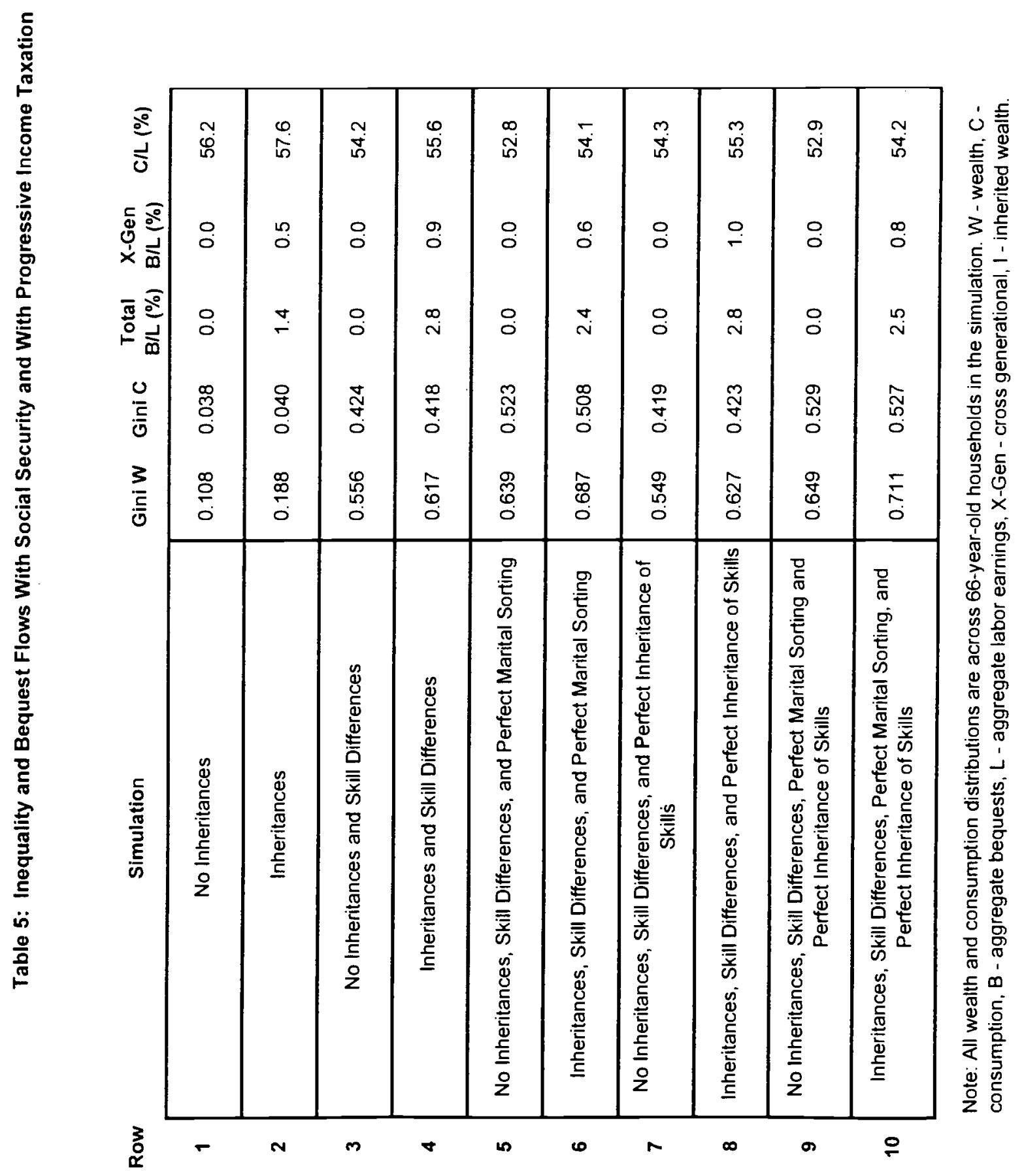




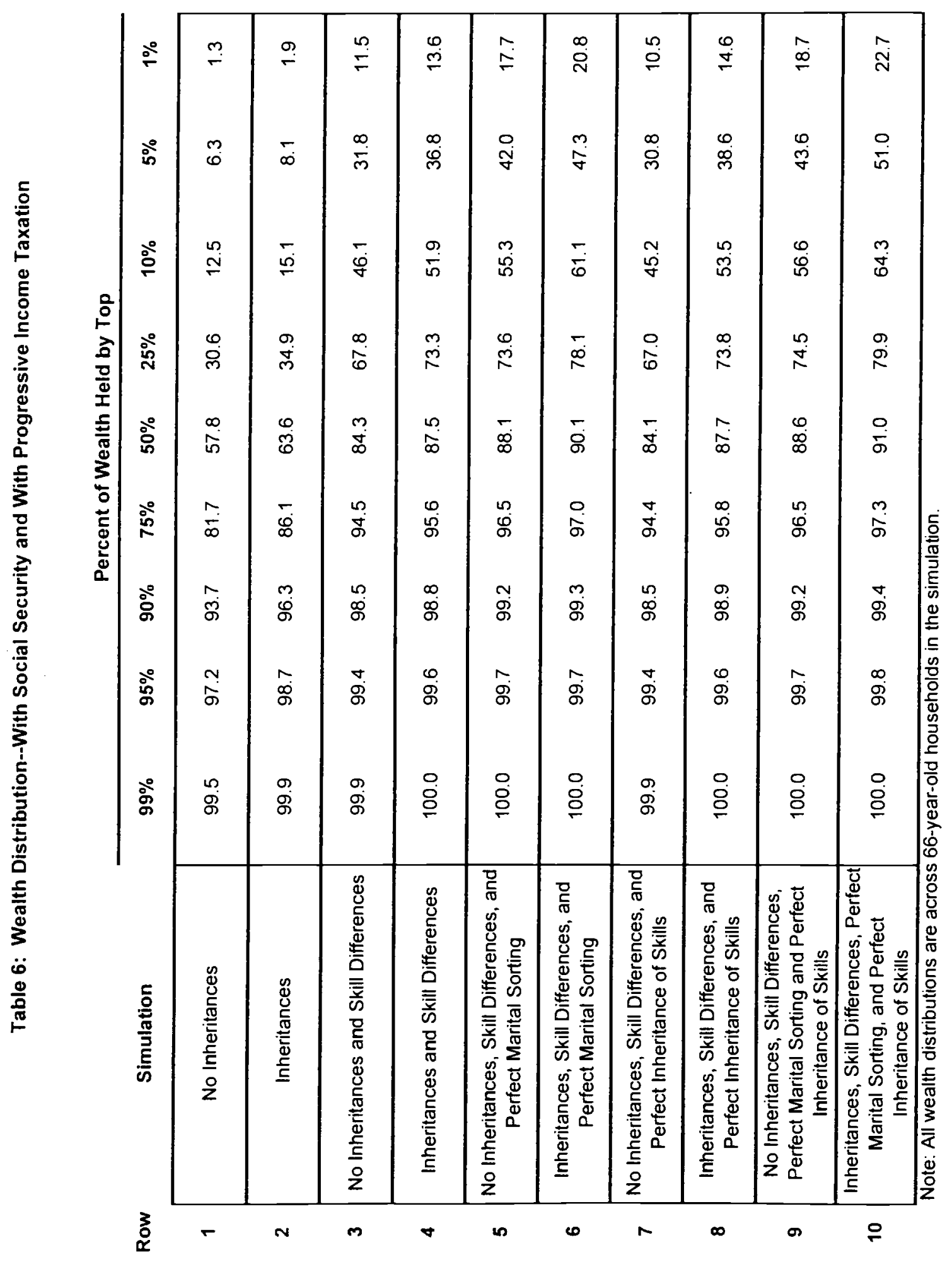




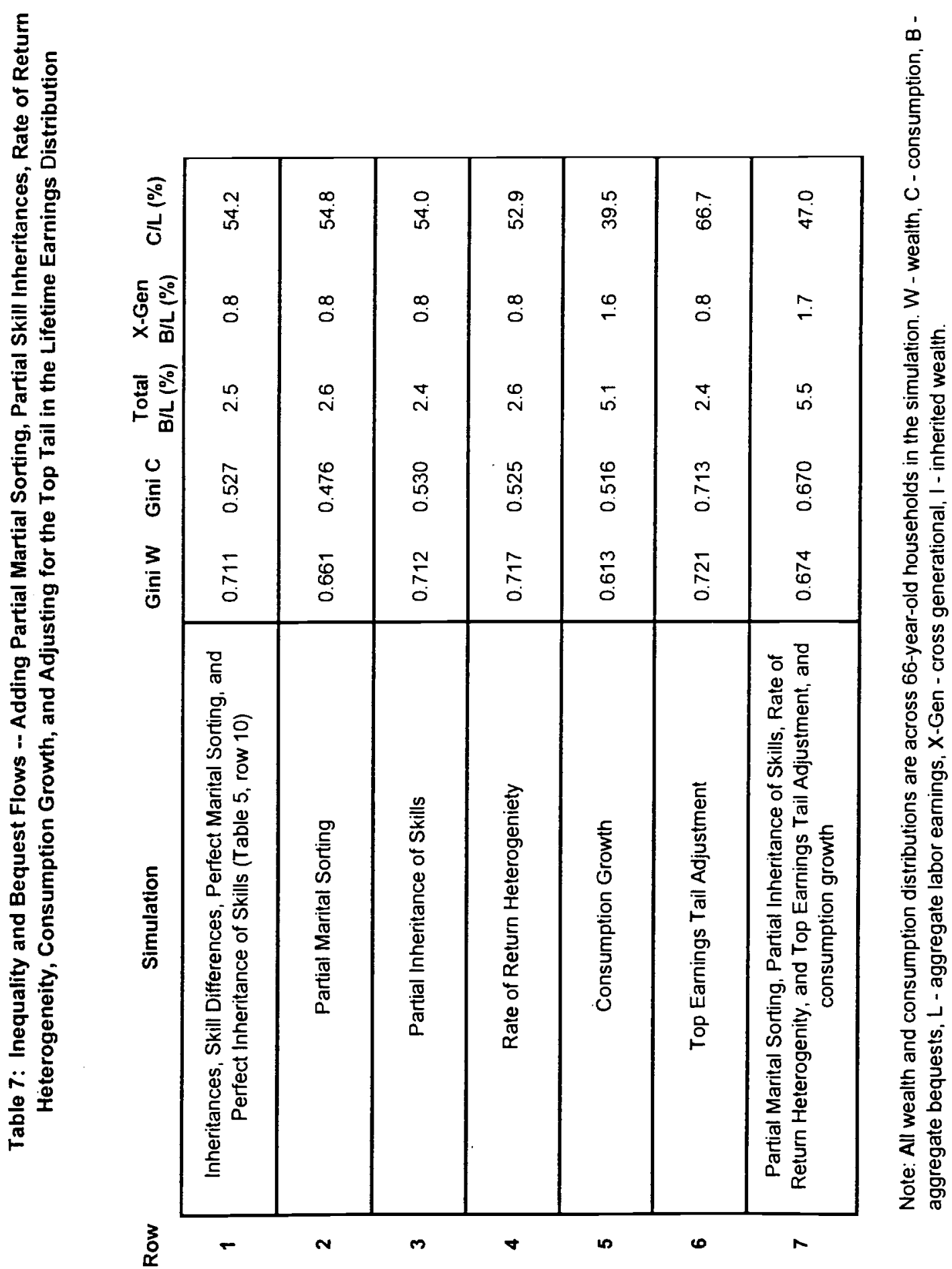




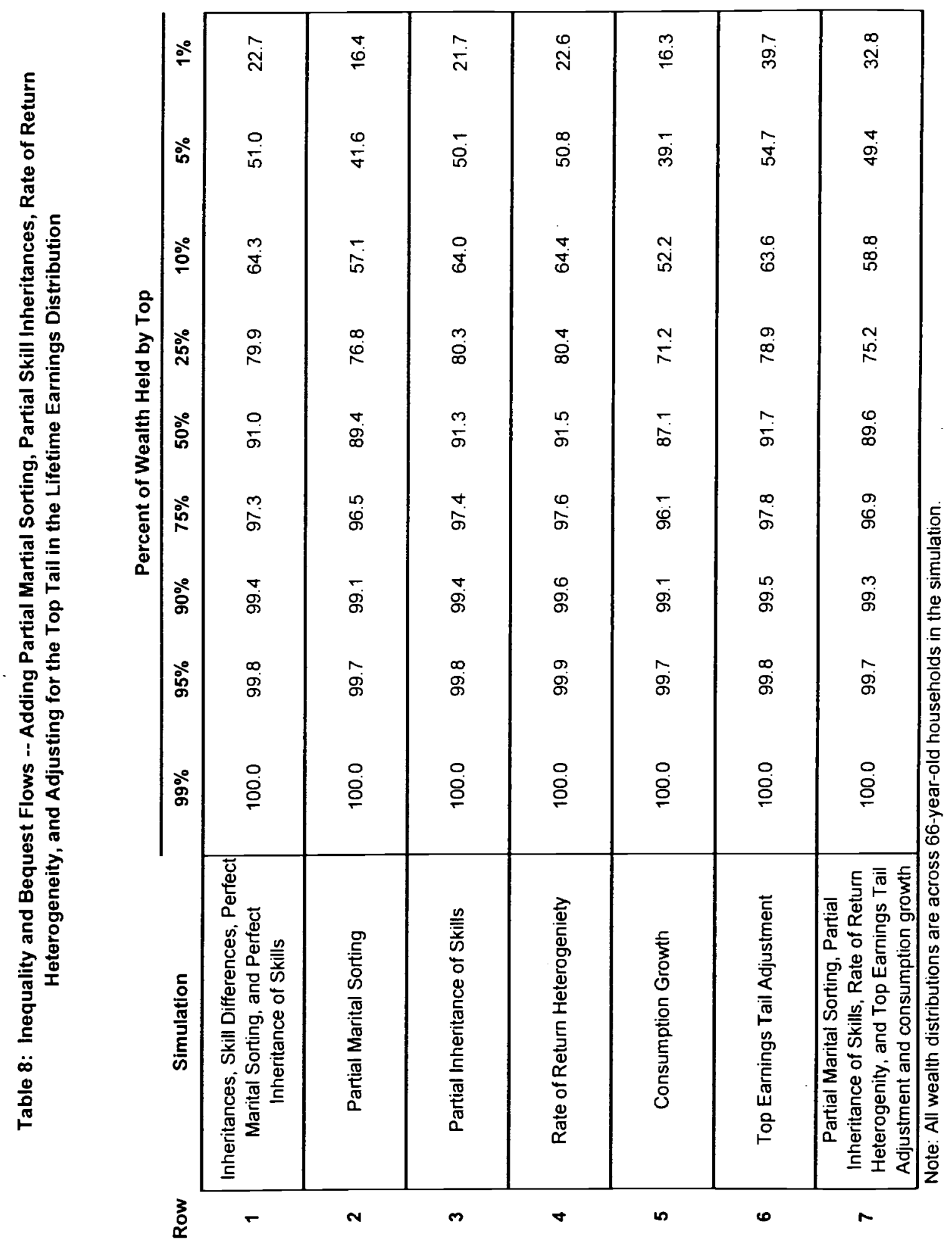




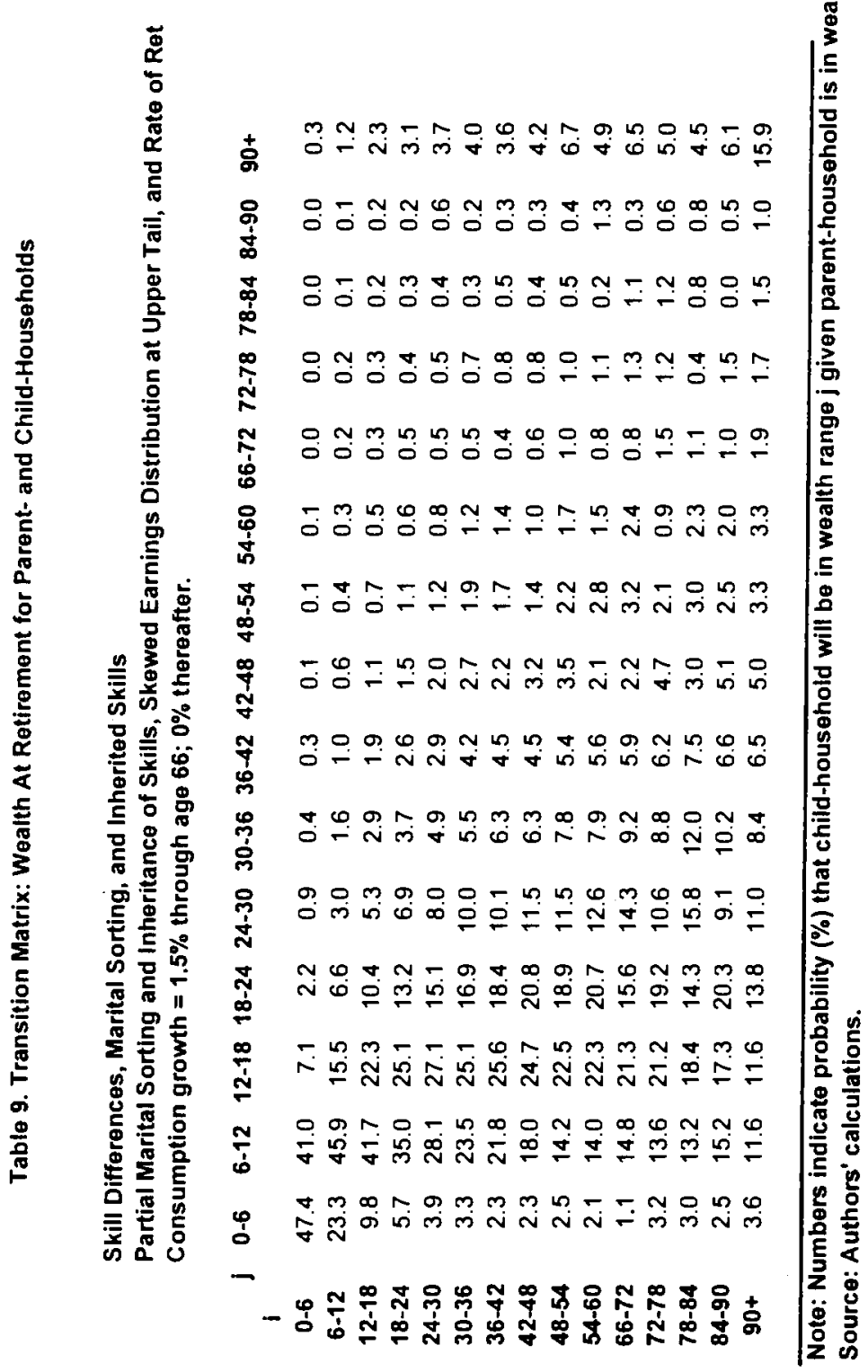

